\title{
MAPEAMENTO DA COBERTURA ARBÓREO-ARBUSTIVA EM QUATRO BAIRROS DA CIDADE DE UBERLÂNDIA- MG
}

\author{
Guilherme Coelho Melazo ${ }^{1}$, Luiz Nishiyama² \\ (recebido em 26.02.2009 e aceito para publicação em 10.06.2010)
}

\section{RESUMO}

Este artigo tem por finalidade apresentar um diagnóstico da situação da cobertura arbórea arbustiva em quatro bairros da cidade de Uberlândia-MG, localizada na mesorregião do Triângulo Mineiro e Alto Paranaíba. Foi realizado o mapeamento da cobertura vegetal e posteriormente calculados índices ambientais a fim de conhecer a distribuição, conectividade e a área ocupada por esse elemento natural nos bairros Morumbi, Santa Mônica, Jardim Karaíba e Centro. Os resultados apontam para áreas com uma quantidade insuficiente de cobertura vegetal (de 3 a 13\%) apresentando-se de maneira geral, mal distribuída e desconexa. O índice de cobertura vegetal por habitante variou entre $7,5 \mathrm{~m}^{2} \mathrm{e}$ $168,95 \mathrm{~m}^{2}$. Ressalta-se a importância do uso de geotecnologias aplicadas a estudos urbanos auxiliando os gestores públicos na tomada de decisões.

Palavras - chave: planejamento urbano, cobertura vegetal, índices ambientais, Sistema de Informação Geográfica.

\footnotetext{
${ }^{1}$ Geógrafo - Instituto de Geografia da Universidade Federal de Uberlândia. Mestre em Engenharia Civil - Universidade Federal de Uberlândia. E-mail: geomelazo@yahoo.com.br

${ }^{2}$ Doutor em Geotecnia - Universidade de São Paulo. Professor Adjunto III - Universidade Federal de Uberlândia
} 


\section{MAPPING OF THE PLANT COVERING IN FOUR NEIGHBORHOODS OF THE CITY OF UBERLÂNDIA- MG}

\section{ABSTRACT}

This article has purpose to present a diagnosis of tree-bush covering situation in four neighborhoods in the city of Uberlândia-MG, located in Triângulo Mineiro and Alto Paranaíba mesoregion. First, the plant covering mapping was accomplished and later was calculated the environmental index in order to analyze the distribution, connectivity and occupied area for this natural element in neighborhood of Morumbi, Santa Mônica, Jardim Karaíba and the downtown area. The results show areas with an insufficient plant covering amount (3 to 13\%) presenting itself, badly distributed and disconnected. The vegetal covering index for inhabitant varied between $7,5 \mathrm{~m}^{2}$ and $168,95 \mathrm{~m}^{2}$. The importance of geotechnologies applied in urban studies is highlighted, assisting the public power in city planning and environmental management.

Keywords: city planning, vegetal covering, environmental index, Geographic Information System 


\section{INTRODUÇÃO}

A dinâmica urbana juntamente com os efeitos da urbanização, entendidos aqui, pelo aumento físico da malha urbana; industrialização; necessidade de incrementos à infraestrutura; adensamento urbano; verticalização; substituição gradual dos espaços naturais por espaços construídos têm causado grandes modificações na paisagem e provocando inúmeras conseqüências sobre o equilíbrio do ambiente urbano. A cobertura vegetal, principalmente, quando constituída de espécies arbóreas, conduz a uma ampla gama de benefícios e funções ambientais. Entretanto, segundo Attwel (2000) a vegetação urbana, encontrada na forma de arborização de calçadas, nos canteiros que acompanham o sistema viário, nos quintais, nas praças e parques, tem sido convencionalmente considerada apenas para fins de valorização visual das cidades.

Cavaleiro et al. (1999), propõe um conceito ao termo cobertura vegetal, como sendo a projeção do verde em cartas planimétricas que pode ser identificada por meio de fotografias aéreas, sem auxilio de esteroscopia. A escala da foto deve acompanhar os índices de cobertura vegetal; deve ser considerada a localização e a configuração das manchas (em mapas). Considera-se toda a cobertura vegetal existente nos três sistemas de espaços (construídos, livres e de integração).

Nucci e Cavalheiro (1999) citam várias funções desempenhadas pela vegetação na cidade, como a estabilização de determinadas superfícies, obstáculo contra o vento, proteção da qualidade da água, filtração do ar, equilíbrio do índice de umidade, diminuição da poeira em suspensão, redução dos ruídos, proteção das nascentes e mananciais, organização e composição dos espaços no desenvolvimento das atividades humanas, entre outras.

O presente estudo teve como objetivo apresentar um diagnóstico da cobertura arbóreo-arbustiva a fim de conhecer a distribuição, conectividade e a área ocupada por esse elemento natural a partir da elaboração de produtos cartográficos, assim como avaliar o Índice de Cobertura Vegetal (ICV) e o índice de Cobertura Vegetal por Habitante (ICVH) nos bairros Morumbi, Santa Mônica, Jardim Karaíba e Centro.

\section{ÁREA DE ESTUDO}

Localizado na porção sudoeste do Estado de Minas Gerais na região do Triângulo Mineiro, o município de Uberlândia encontra-se entre as coordenadas geográficas de $18^{\circ} 55^{\prime \prime}$

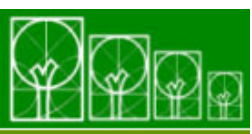

$\mathbf{S} \cdot \mathbf{B} \cdot \mathbf{A} \cdot \mathbf{U}$ Soc. Bras. de Arborização Urbana

REVSBAU, Piracicaba - SP, v.5, n.2, p.52-66, 2010 
- 19 `30’ de latitude sul e, 4750’ - 48 '50’ de longitude oeste de Greenwich. A área do município é de $4.115 \mathrm{Km}^{2}$ sendo $219 \mathrm{Km}^{2}$ na área urbana.

O município de Uberlândia está situado no domínio dos Planaltos e Chapadas da Bacia Sedimentar do Paraná, estando inserido na subunidade do Planalto Meridional da Bacia do Paraná caracterizando-se por apresentar relevo tabular, levemente ondulado, com altitude inferior a 1.000 m (RADAMBRASIL, 1983). Ab' Saber (1971) denominou a área como fazendo parte de um conjunto global chamado Domínio dos Chapadões Tropicais do Brasil Central.

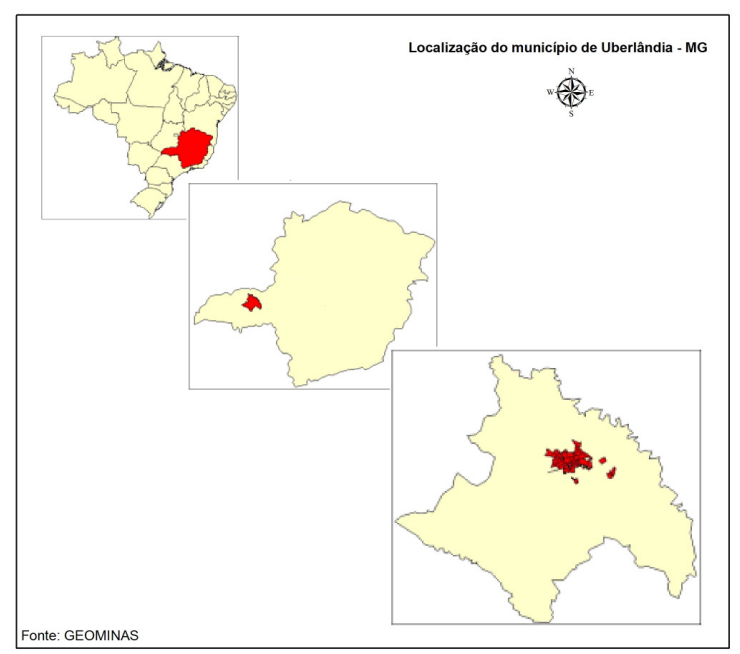

Fonte: GeoMINAS- Governo do Estado de Minas Gerais.

FIGURA 1 - Localização do município de Uberlândia no Estado de Minas Gerais.

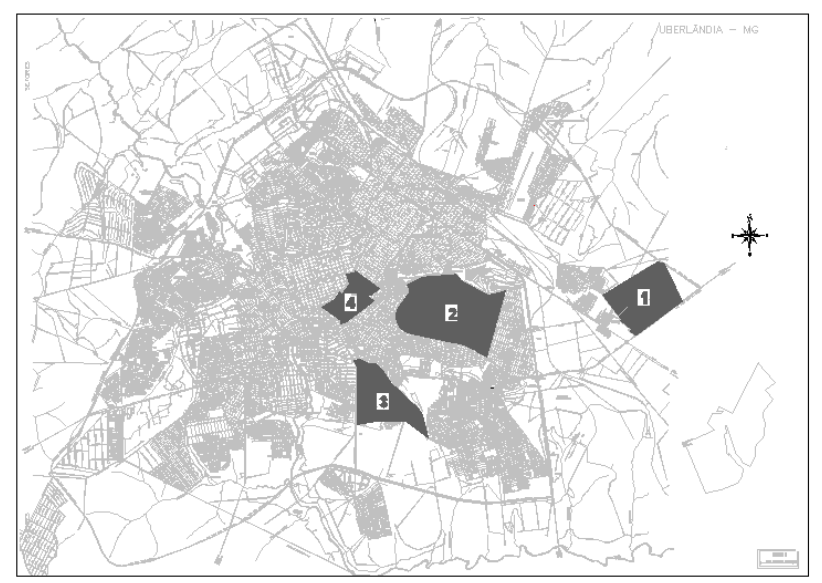

Fonte: Secretaria de Planejamento Urbano e Meio Ambiente (PMU)

FIGURA 2 - Localização dos Bairros Morumbi (1), Santa Mônica (2), Jardim Karaíba (3) e Centro (4) em Uberlândia - MG. 


\section{MATERIAIS E MÉTODOS}

De acordo com Rosa (2003), os sistemas de sensoriamento remoto, hoje disponíveis, permitem a aquisição de dados de forma global, confiável, rápida e repetitiva, sendo estes dados de grande importância para o levantamento, mapeamento e utilização das informações de uso e ocupação do solo de uma dada região.

Por meio das técnicas de processamento digital de imagens, aplicou-se uma série de rotinas computacionais aos dados, desde a sua entrada, passando pela edição, armazenamento de modo a permitir a extração de informações específicas de interesse da pesquisa e elaboração de mapas temáticos. A interpretação visual e posterior poligonização manual do atributo cobertura vegetal foi o método operacional adotado, entendido aqui como um procedimento mais adequado ao objetivo da pesquisa e que chegou a um resultado final mais próximo da realidade.

Santos (2004), afirma que um mapa permite observar as localizações, as extensões, os padrões de distribuição de elementos e atributos, além de representar generalizações e extrapolações. Principalmente, deve favorecer a síntese, a objetividade, a clareza da informação e a sistematização dos elementos a serem representados. Garantidas essas qualidades, os mapas podem ser um bom instrumento de comunicação entre planejadores e atores sociais do planejamento.

Foram utilizados, para a realização da pesquisa, os seguintes materiais:

* Mapa Base da área urbana do município de Uberlândia (2008 / 1:100.000) Secretaria Municipal de Planejamento Urbano e Meio Ambiente - SEPLAMA;

* Fotografias Aéreas Georeferenciadas (Estio Engenharia Aerolevantamento (2004) Escala: 1:8.000) das Regiões de Interesse (bairros Santa Mônica, Morumbi, Jardim Karaíba e Centro) - Secretaria Municipal de Planejamento Urbano e Meio Ambiente (SEPLAMA);

* Software SPRING 4.3.

Ressalta-se que a pesquisa mensurou especificamente as copas das árvores (porte arbóreo e arbustivo) os quais foram utilizados para calcular os índices ambientais propostos a seguir.

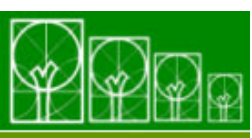

S $\cdot \mathbf{B} \cdot \mathbf{A} \cdot \mathbf{U}$ Soc. Bras. de Arborização Urbana 
a) Índice de Cobertura Vegetal (\%): É a proporção de área coberta com vegetação (Copa das Árvores/arbustos) em função da área total de uma cidade ou de um setor urbano, ou ainda uma paisagem urbana específica. Trata-se de um indicador de qualidade ambiental representado pela fórmula:

$$
I C V=\frac{\text { superfície total da copa das árvores / arbustos }\left(\mathrm{m}^{2}\right)}{\text { superfície total da área }\left(\mathrm{m}^{2}\right)}
$$

b) Índice de Cobertura Vegetal por Habitante ( $\left.\mathrm{m}^{2} / \mathrm{hab}\right)$ : É a proporção de área coberta com vegetação (copa das árvores/arbustos) pela quantidade de pessoas total de uma cidade ou de um setor urbano, ou ainda uma paisagem urbana específica. Trata-se de um indicador de qualidade ambiental representado pela fórmula:

$I C V H=\frac{\text { superfície total da copa das árvores / arbustos }\left(m^{2}\right)}{\text { quantidade total de habi } \tan \text { tes }}$

Os índices calculados buscaram retratar as condições do ambiente no ano de 2004 , podendo, dessa forma, estabelecer metas que se desejam alcançar avaliando variações temporais e que possam servir como um referencial comparativo em futuras pesquisas. Fujimoto (2001) argumenta que através da análise da evolução da cobertura vegetal e uso da terra é possível avaliar as transformações ocorridas no espaço urbano. Os registros históricos revelam a evolução da cobertura vegetal e do uso do solo, pois são reflexos da apropriação da natureza pela sociedade e suas relações, podendo indicar um cenário das condições e qualidade ambiental.

\section{Breve histórico dos bairros pesquisados}

A história do planejamento e gestão ambiental de Uberlândia, relativo ao conjunto de ações realizadas em prol do meio ambiente local, oferece subsídios para compreender o contexto atual da estrutura técnica, administrativa e legal existente, bem como suas ações práticas. A esse conjunto de ações (criação de instrumentos normativos, órgãos executivos, projetos e programas) pode ser denominado como Políticas Ambientais. Uberlândia estabeleceu uma política ambiental de fato, somente a partir do início da década de 1980. (MENDONÇA e LIMA, 2000). Nessa mesma década, os loteamentos da cidade de Uberlândia passaram por um processo de integração, culminando na criação dos Bairros 
Integrados, no qual os loteamentos vizinhos, com nomes distintos passaram a ter a mesma denominação, conforme demonstra a tabela1.

TABELA 1 - Bairros Integrados de Uberlândia - MG

\begin{tabular}{|c|c|c|c|c|}
\hline Setor & Loteamento & Data de Aprovação & Bairro Integrado & $\begin{array}{c}\text { Data de } \\
\text { Integração }\end{array}$ \\
\hline Leste & $\begin{array}{l}\text { Santa Mônica - setor A } \\
\text { Santa Mônica - setor B } \\
\text { Santa Mônica - setor C } \\
\text { Conjunto Universitário } \\
\text { Jardim Parque Sabiá } \\
\text { Jardim Finotti } \\
\text { Progresso } \\
\text { Fábio Felice } \\
\text { Santos Dumont - } \\
\text { prolongamento } \\
\text { Vila Santos Dumont }\end{array}$ & 1963 a 1979 & Santa Mônica & $21 / 12 / 1993$ \\
\hline Leste & $\begin{array}{l}\text { Santa Mônica II - setor A } \\
\text { Santa Mônica II - setor B } \\
\text { Santa Mônica II - setor C }\end{array}$ & 1991 & Morumbi & $30 / 08 / 1995$ \\
\hline Sul & $\begin{array}{l}\text { Altamira (parte) } \\
\text { Jardim Inconfidência } \\
\text { (parte) } \\
\text { Jardim Indaiá } \\
\text { Jardim das Acácias } \\
\text { Vila do Sol } \\
\text { Jardim Karaíba } \\
\text { Ipanema Sul }\end{array}$ & 1980 & Jardim Karaíba & $20 / 03 / 1995$ \\
\hline Central & $\begin{array}{l}\text { Vila Oswaldo (parte) } \\
\text { Outros não identificados }\end{array}$ & - & Centro & $26 / 04 / 1995$ \\
\hline
\end{tabular}

Fonte: Adaptado - Secretaria Municipal de Planejamento e Desenvolvimento Urbano / Divisão de Planejamento Social / Divisão de Planejamento Urbano e Rural (2006)

A escolha dos bairros foi condicionada, a princípio, às características sócioeconômicas, área $\left(\mathrm{m}^{2}\right)$, infra-estrutura e equipamentos instalados, atributos estes, distintos em cada um dos bairros, assim como a data de aprovações dos respectivos loteamentos.

O bairro Morumbi, localizado no setor leste da cidade de Uberlândia, foi criado a partir da construção de casas do tipo embrião com recursos do Plano de Ação Imediata de Habitação, programa habitacional destinado à população de baixa renda. O bairro, de fato periférico, apresenta deficiências na infra-estrutura e saneamento básico e equipamentos públicos. Também no setor leste, o bairro Santa Mônica abriga uma variedade enorme de 
equipamentos urbanos. Tornou-se há alguns anos, sub-centro nesse processo de descentralização de atividade políticas, econômicas e culturais. Atualmente existe a predominância de residências de médio padrão construtivo, tanto em relação ao tamanho do lote e a área construída. No bairro estão localizados a Universidade Federal de Uberlândia, a Prefeitura Municipal, o Parque Municipal do Sabiá, o Estádio Municipal João Havelange e a, além de hipermercados, grande quantidade e variedade de comércio e serviços como lojas, bares e restaurantes. O Bairro Jardim Karaíba caracteriza-se como um bairro residencial de alto padrão sócio-econômico localizado no Setor Sul de Uberlândia. Grande parte das casas e condomínios possui áreas permeáveis (jardins frontais e quintais com arbustos e árvores ornamentais) valorizando economicamente o terreno e a área do bairro propriamente dita. A presença de condomínios horizontais é outra característica desse bairro, que tem nesse tipo de empreendimento, uma alternativa de conforto, segurança, com maior qualidade ambiental. Por fim o Centro, um bairro muito valorizado por seus moradores e comerciantes, apresenta uma infra-estrutura totalmente instalada, rede de esgotosanitário, abastecimento de água, iluminação, redes de energia, calçamentos, construções existentes e alto grau de urbanização. É um bairro caracterizado pelo setor de serviços e comércio, instituições financeiras.

\section{O Horto Municipal de Uberlândia}

Uma estrutura importante no contexto do planejamento urbano ambiental em Uberlândia, pertencente à Secretaria Municipal de Meio Ambiente é Horto Municipal, que desde 1985 contribui para produção, beneficiamento, manutenção e distribuição de milhares de mudas de árvores na cidade. O horto é responsável pelo gerenciamento e execução de corte e poda de árvores, atividades de Educação Ambiental em parques e outros espaços livres, assim como o Disk Árvore, um serviço que proporciona a população o plantio de mudas na calçada de sua residência gratuitamente. Entre as espécies mais adequadas utilizadas para o plantio em calçadas, canteiros centrais de vias públicas e praças da cidade de Uberlândia, o Horto Municipal conta com as seguintes espécies de pequeno, médio e grande porte.

TABELA 2 - Espécies arbóreas de pequeno porte

\begin{tabular}{cclll}
\hline Nome & Nome Científico & Altura $(\mathbf{m})$ & Época & Cor \\
\hline Calistemon & Callistemon viminalis & 3 a 5 & jan. /dez. & Vermelha \\
\hline
\end{tabular}




\begin{tabular}{lllll}
\hline $\begin{array}{l}\text { Flamboyant } \\
\text { mirim }\end{array}$ & Caesalpinia pulcherrima & 3 a 5 & out./jan. & amarela/vermelha \\
\hline Murta & Murraya exotica & 3 a 5 & out./jan. & branca \\
\hline Resedá & Lagerstroemia indica & 4 a 6 & out./mar. & branca/rósea \\
\hline Hibisco & Hibiscos rosa -sinensis & 3 a 5 & jan./dez. & branca/rósea \\
\hline Fonte: & Sucretaria &
\end{tabular}

Fonte: Secretaria Municipal de Planejamento Urbano e Meio Ambiente

TABELA 3- Espécies arbóreas de porte médio

\begin{tabular}{lllll}
\hline \multicolumn{1}{c}{ Nome } & Nome Científico & $\begin{array}{l}\text { Altura } \\
(\mathbf{m})\end{array}$ & Época & Cor \\
\hline Alfeneiro & Ligustrum japonicus & 6 a 8 & out./dez & branca \\
\hline Cássia imperial & Cassia fistula & 5 a 8 & dez./mar. & amarela \\
\hline Aroiera Salsa & Schinus molle & 6 a 8 & dez./fev. & esverdeada \\
\hline Magnólia amarela & Michelia champaca & 6 a 10 & mar./fev & amarela \\
\hline Quaresmeira & Tibouchina granulosa & 5 a 7 & dez./jul. & rosa/roxa \\
\hline
\end{tabular}

Fonte: Secretaria Municipal de Planejamento Urbano e Meio Ambiente

TABELA 4 - Espécies arbóreas de grande porte

\begin{tabular}{lllll}
\hline \multicolumn{1}{c}{ Nome } & Nome Científico & Altura (m) & Época & Cor \\
\hline Ipê roxo & $\begin{array}{l}\text { Tabebuia } \\
\text { impetiginosa }\end{array}$ & 6 a 8 & set. / out. & rosa / lilás \\
\hline Jacarandá mimoso & $\begin{array}{l}\text { Jacaranda } \\
\text { mimosaefolia }\end{array}$ & 6 a 12 & set. / dez. & roxa \\
\hline Mirindiba & $\begin{array}{l}\text { Lafoensia } \\
\text { glyptocarpa }\end{array}$ & 6 a 10 & nov. / fev. & branca / rósea \\
\hline Oiti & Moquilea tomentosa & 6 a 10 & jul. / dez. & branca \\
\hline Pau ferro & Caesalpinia ferrea & 12 & ago. / dez. & amarela \\
\hline
\end{tabular}

Fonte: Secretaria Municipal de Planejamento Urbano e Meio Ambiente

\section{RESULTADOS E DISCUSSÕES}

Estudos sobre vegetação urbana na Alemanha estabeleceram objetivos para a cobertura vegetal baseados nas melhores práticas executadas em Munique. Para as áreas residenciais de baixa verticalização a meta para Munique é de $50 \%$ de cobertura vegetal, sendo $25 \%$ de cobertura de árvores e arbustos, para área ocupada por complexo de apartamentos, a meta é de $30 \%$ de cobertura vegetal, sendo $15 \%$ para árvores e arbustos, para as áreas industriais, a meta é de $20 \%$ de cobertura vegetal com $10 \%$ para árvores e arbustos; portanto, para Munique, $50 \%$ de toda cobertura vegetal deveria ser constituída por 
floresta. (PAULEIT \& DUHME, 1995 apud ATTWELL, 2000). Oke (1973) apud Lombardo, (1985) estima que um índice de cobertura vegetal na faixa de 30\% seja o recomendável para proporcionar um adequado balanço térmico em áreas urbanas, sendo que áreas com índice de arborização inferior a $5 \%$ determinam características semelhantes às de um deserto.

A cobertura vegetal existente no bairro Morumbi representada na Figura 3 apresentase de forma geral desconexa, localizada em grande parte no interior dos quarteirões, em quintais das áreas particulares e em menor escala nos calçamentos, portanto muito fragmentada. O valor obtido através do Índice Cobertura Vegetal (ICV) do bairro Morumbi foi $3 \%$, enquanto o valor encontrado para Índice de Cobertura Vegetal por Habitante (ICVH) foi $7,5 \mathrm{~m}^{2}$ por habitante. O resultado do ICV expressa uma insuficiência em relação à quantidade e distribuição das árvores o que interfere diretamente na qualidade ambiental do bairro, principalmente no que diz respeito ao conforto térmico, e aos aspectos estéticos paisagísticos.

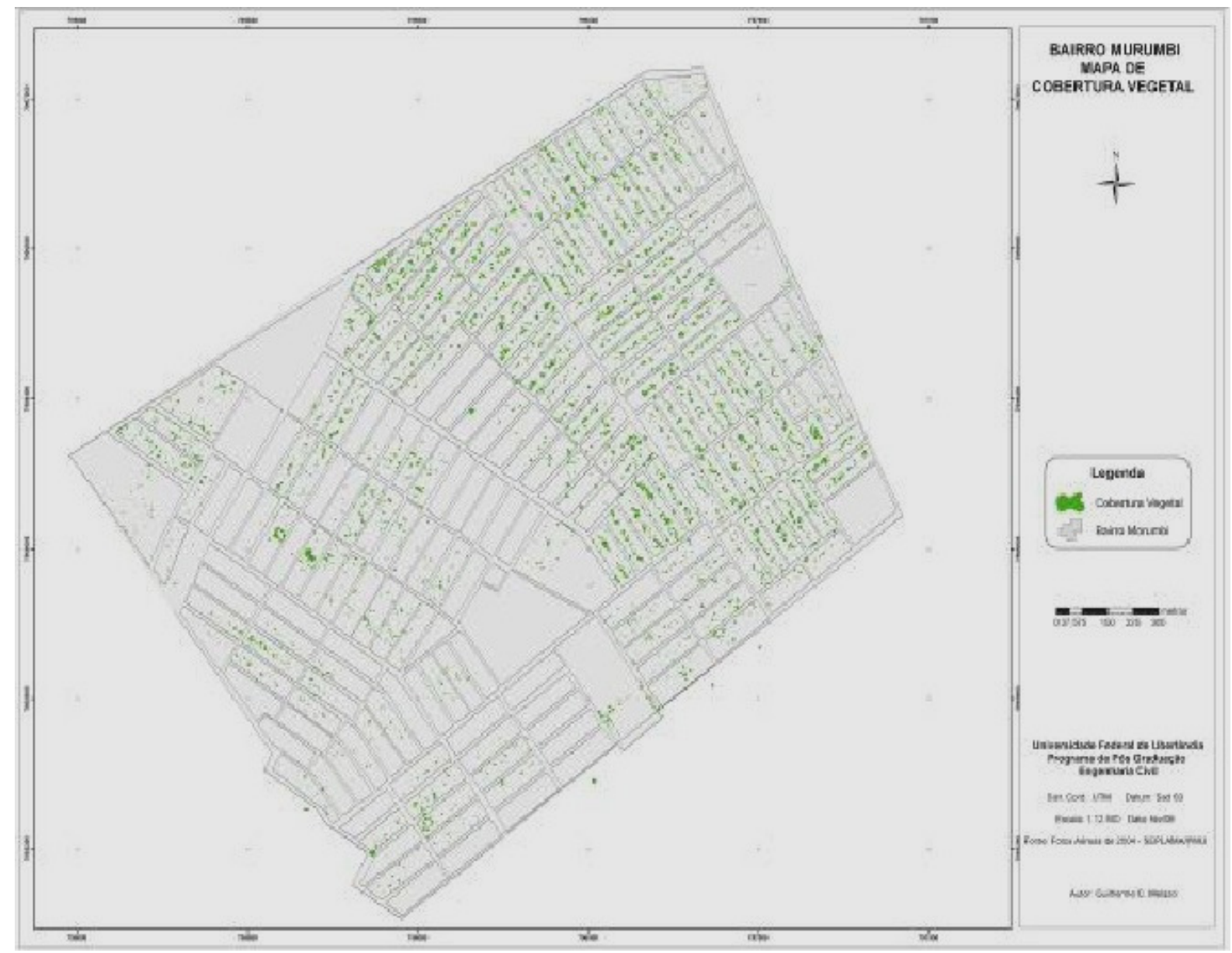


FIGURA 3 - Mapa de cobertura arbóreo-arbustiva no bairro Morumbi em Uberlândia - MG

No bairro Santa Mônica, nota-se que a cobertura vegetal da está distribuída de forma bem heterogênea, isolada e bem fragmentada entre terrenos e edificações, parte nos quintais de áreas particulares, praças e em canteiros centrais (Figura 4).

O resultado do ICV foi 8,3\%, refletindo uma insuficiência em relação à quantidade de árvores. O resultado do ICVH foi de $14,6 \mathrm{~m}^{2}$. De acordo com informações obtidas no Horto Municipal (setor de fiscalização) o Santa Mônica é o bairro com o maior número de ocorrência e solicitações de corte e poda de árvores. Esse fato está relacionado a diversos fatores como a condição fitossanitária, ao tempo de vida da árvore, largura de calçadas inadequadas, a inadequação de espécies ao local, tamanho da cova, presença de fiação entre outros.

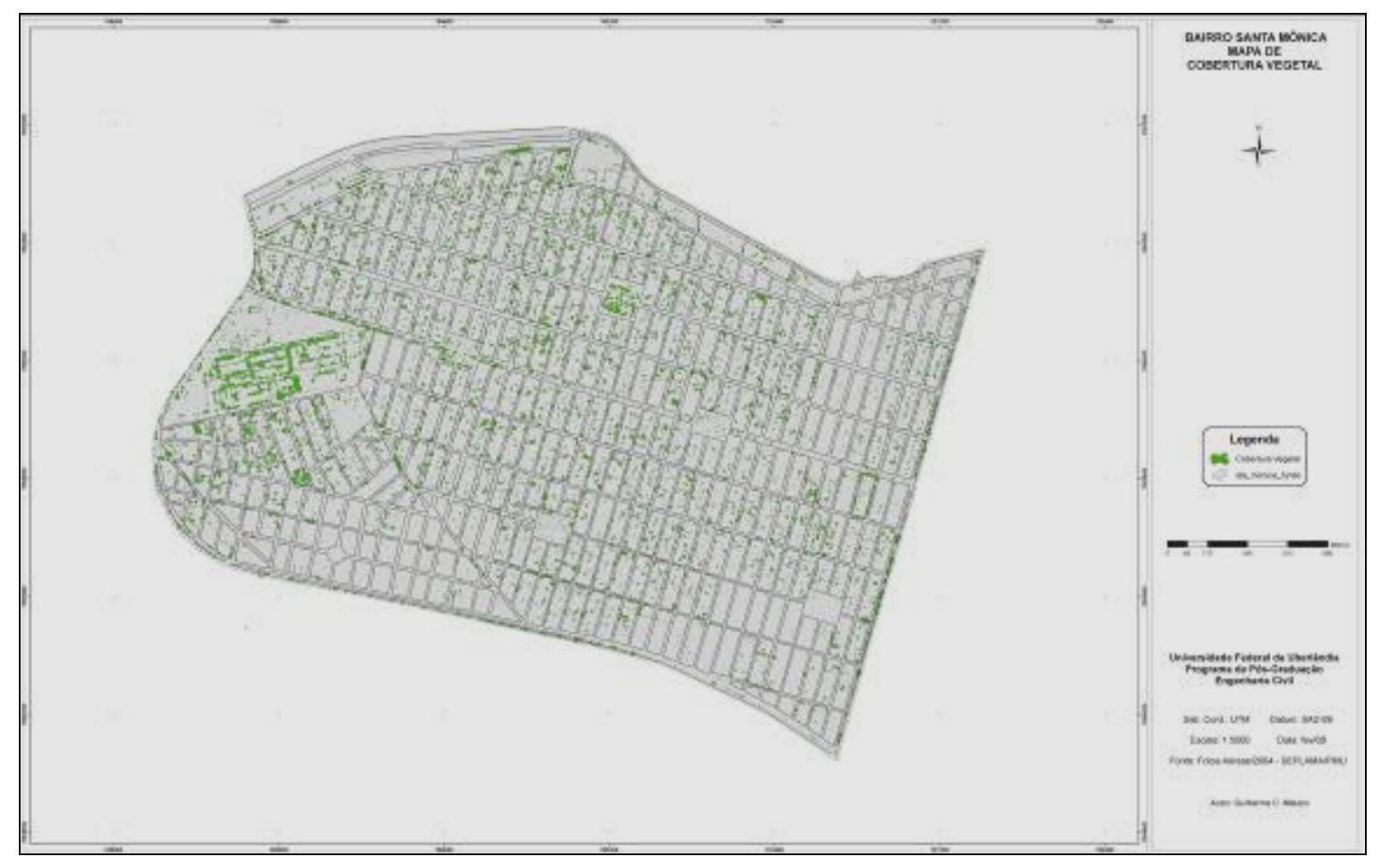

FIGURA 4 - Mapa de cobertura arbóreo-arbustiva no bairro Santa Mônica em Uberlândia MG.

A cobertura vegetal do bairro Jardim Karaíba apresenta-se desconexa, bem fragmentada (Figura 5). É possível perceber, na área central e noroeste do mapa áreas mais densamente arborizadas. O resultado do ICV do bairro Jardim Karaíba foi 13\%, o maior 
índice calculado entre os bairros pesquisados. O alto valor obtido no $\mathrm{ICVH}$, de $168,95 \mathrm{~m}^{2}$ por habitante para o bairro Jardim Karaíba, se deve ao fato de maioria das casas apresentarem jardins com árvores frutíferas ou não, outras áreas isoladas apresentando fragmentos de vegetação nativa, bem como a relação número de habitantes e área do bairro, determinantes para o resultado.

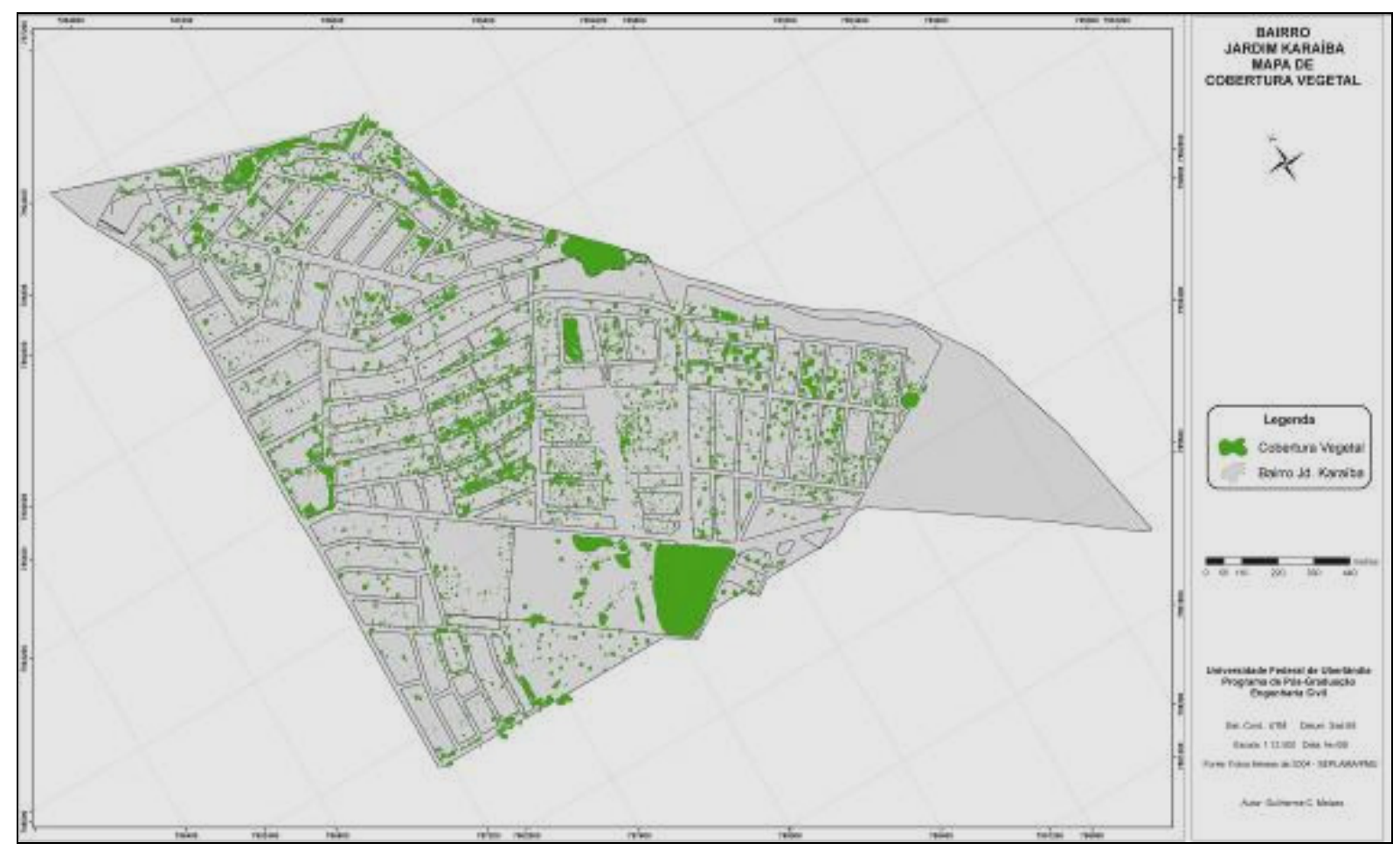

FIGURA 5 - Mapa de cobertura arbóreo-arbustiva no bairro Jardim Karaíba em Uberlândia MG.

No que diz respeito à arborização urbana do centro, pode-se dizer que ela ocorre predominantemente nas praças públicas, praticamente os únicos locais onde se torna possível o desenvolvimento e manejo adequado da vegetação, constituindo "ilhas de vegetação". Em proporção bem menor, é possível notar a sua presença em calçadas ou em fundo de quintais, além de jardins de edifícios ou casas, apresentando-se mal distribuída, isolada, desconexa e muito fragmentada (Figura 6).

Dizer em melhorar a qualidade ambiental do centro da cidade no que se refere à cobertura vegetal, tornou-se algo muito complicado, em função da indisponibilidade de espaço destinado ao plantio, além de outras prioridades notórias como a acessibilidade de pedestres, fluxo e transporte de automóveis, entre outros. O resultado do ICV do bairro Centro foi $7 \%$, enquanto o ICVH foi $13,47 \mathrm{~m}^{2}$ por habitante, o que está diretamente relacionado à proporção população residente e a pequena área do bairro 


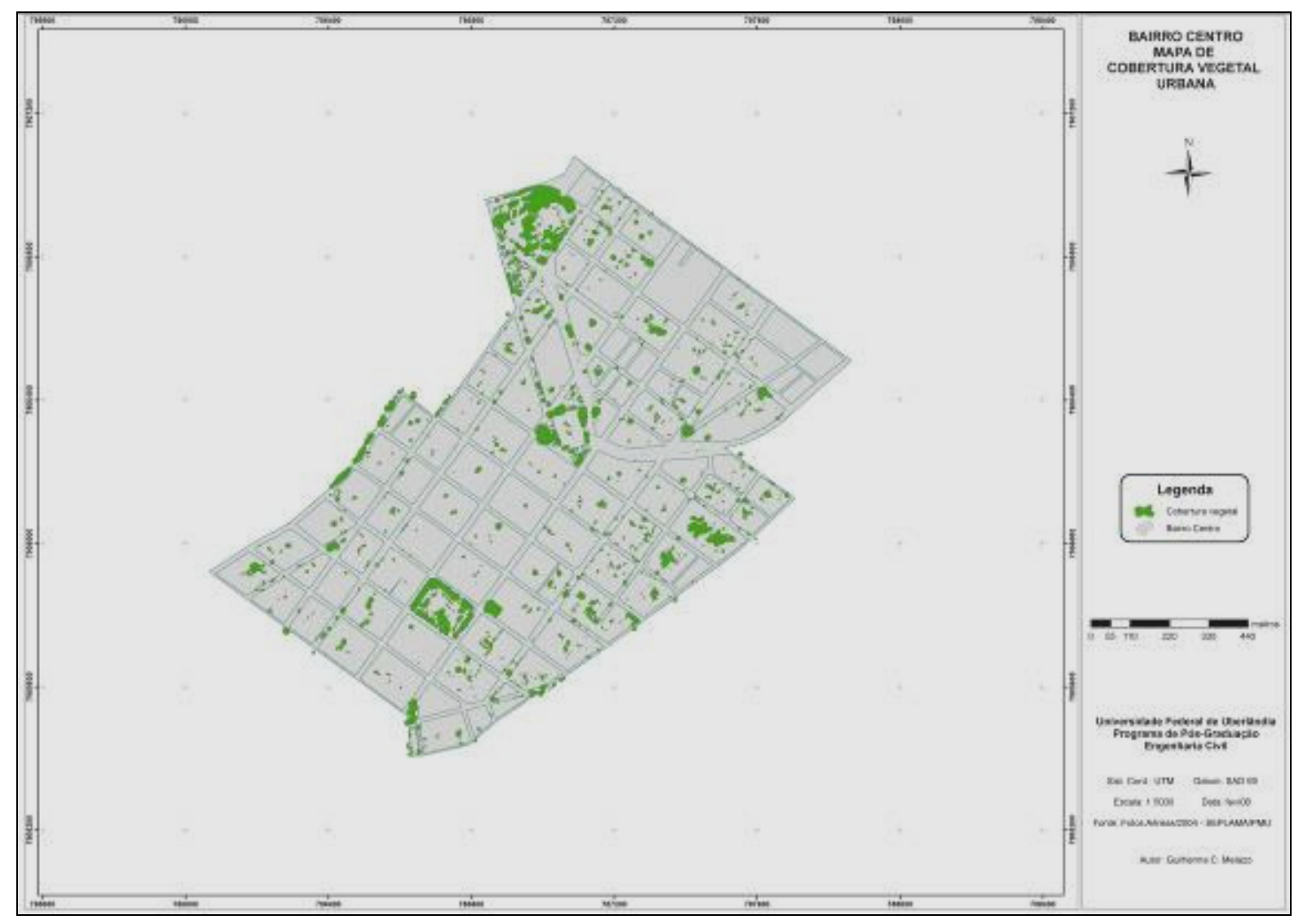

FIGURA 6 - Mapa de cobertura arbóreo-arbustiva no bairro Centro em Uberlândia- MG

Os resultados apontam para áreas com uma quantidade insuficiente de cobertura vegetal (de 3 a 13\%) apresentando-se de maneira geral, mal distribuída e desconexa. Se comparados aos 50\% de cobertura vegetal, proposto por Pauleit \& Duhme (1995 apud ATTWELL, 2000), os valores encontrados mostraram-se muito inferiores. Todavia, ressaltase que a análise da cobertura foi realizada especificamente com as copas das árvores (porte arbóreo e arbustivo), sem considerar a vegetação herbácia. Os resultados dos índices de cobertura vegetal por habitante variaram entre $7,5 \mathrm{~m}^{2}$ e $168,95 \mathrm{~m}^{2}$.

\section{CONCLUSÕES}

O mapeamento da cobertura vegetal associado aos índices calculados é de desejável alerta para o poder público e sociedade civil. Os resultados alcançados podem delinear planos de ação para a cobertura vegetal, bem como o manejo dessa vegetação, apontando a importância que ela exerce no ambiente urbano. Torna-se fundamental o 
estabelecimento de metas a partir dos dados iniciais obtidos, de forma a implementar programas e projetos como, por exemplo, um Plano de Arborização Municipal. Essas diretrizes devem ter como ponto de partida, novas leis específicas para arborização viária, cobertura vegetal urbana, áreas verdes, planos de arborização, vontade política e interesse social, entre outros aspectos sócio-ambientais e uma mudança de paradigma em relação aos equipamentos urbanos.

Deve-se contemplar nesses planos e ações, as características físicas de cada rua, bairro específico, considerando as limitações físicas e biológicas que o local impõe ao crescimento das árvores, definição de critérios para a escolha das espécies mais adequadas, definir a espécie de árvore que melhor se adeqüe ao local com o objetivo de minimizar os impactos da urbanização sobre a vegetação e melhorar a qualidade ambiental dos centros urbanos.

\section{REFERÊNCIAS BIBLIOGRÁFICAS}

AB'SABER, Aziz Nacib. Contribuições a Geomorfologia da área dos cerrados. Simpósio Sobre o Cerrado. São Paulo, EDUSP: 97-103, 1971.

ATTWELL, K. Urban land resources and urban planting - case studies from Denmark. Landscape and Urban Planning 52 (2000) 145-163. Disponível em: www.elsevier.com/locate/landurbplan Acesso em: 11/08/2009

BRASIL. MINISTÉRIO DAS MINAS E ENERGIA (1983) Projeto Radam Brasil - Folha SE.22. Rio de Janeiro: MME.

CAVALHEIRO, F.; NUCCI, J.C; GUZZO, P.; ROCHA, Y.T. Proposição de terminologia para o verde urbano. Boletim Informativo da SBAU (Sociedade Brasileira de Arborização Urbana), ano VII, n. 3 - Jul/ago/set de 1999, Rio de Janeiro, p. 7.

GEOMINAS. Minas Gerais: contorno, divisão municipal e sedes municipais. Disponível em: www.geominas.mg.gov.br 
FUJIMOTO, N.S.V.M. Análise ambiental urbana na área metropolitana de Porto Alegre. R.S: Sub-bacia hidrográfica do arroio dilúvio. São Paulo, 2001. 235 p. Tese (Doutorado) - Faculdade de Filosofia, Letras e Ciências Humanas, Universidade de São Paulo.

LOMBARDO, M.A. Ilha de calor nas metrópoles. O exemplo de São Paulo. São Paulo: Hucitec, 1985, 244p.

MENDONÇA, M.; LIMA, S. Histórico da gestão ambiental no município de Uberlândia. In: Caminhos de Geografia (online) 1(1)8-17, set/ 2000 Página 8. Universidade Federal de Uberlândia. Disponível em: www.ig.ufu.br/revista/volume01/artigo02 vol01.pdf . Acesso em $10 / 03 / 2010$

NUCCI, J.C.; CAVALHEIRO, F. Cobertura vegetal em áreas urbanas - conceito e método. GEOUSP 6, São Paulo: Depto. de Geografia/USP, pp. 29-36, 1999.

ROSA. R. Introdução ao sensoriamento remoto. 5 ed., Uberlândia: EDUFU, 2003, 228p.

SANTOS, R.F. Planejamento Ambiental: teoria e prática. São Paulo: Oficina de Textos, 2004.

UBERLÂNDIA. Banco de Dados Integrados - BDI. Uberlândia: Prefeitura Municipal de Uberlândia, 2004.

UBERLÂNDIA. Secretaria Municipal de Meio Ambiente: Prefeitura Municipal de Uberlândia, 2004. 